\title{
Research Paper Validation of two parameter function height diameter models
}

See end of the paper for authors' affiliations

Correspondence to :

\section{Iqbal Jeelani}

Faculty of Basic Sciences, Sher-e-Kashmir University of Agricultural Sciences and Technology of Jammu, Jammu (J\&K) India Email : jeelani.miqbal@ gmail.com

\section{Paper History :}

Received : 27.06.2018;

Revised : 01.08.2018;

Accepted : 13.08 .2018
ABSTRACT : Eleven nonlinear height diameter models were fitted and developed for Pinus trees based on individual tree height and diameter at breast height data $(n=300)$ collected from block Langate of Kashmir province in India. Fitting of height diameter models using non-linear least square regression showed that all the parameters across all models were significant. In order to test the predictive performance of the models 10 - folded cross-validation technique was used in this study. Comparison of AIC, RMSE, ME and Ad- $\mathrm{R}^{2}$ values for the training and validation data showed that most of the non-linear HD models capture the height diameter relationships for Pinus trees. Validation results suggest that Naslund -2 HD model provide the best height predictions in case of Pinus tree.

KEY WORDS : Height, Diameter, Cross validation, Pinus

HOW TO CITE THIS PAPER : Jeelani, M. Iqbal, Sharma, Manish Kr, Bhat, Anil and Gul, Mansha (2018). Validation of two parameter function height diameter models. Res. J. Agric. Eco. \& Stat., 9 (2) : 331-334, DOI : 10.15740/HAS/IRJAES/9.2/331-334. Copyright@ 2018: Hind Agri-Horticultural Society. 